\title{
REAPROVEITAMENTO DE ESTÉRIL DE MINERAÇÃO COMO AGREGADO GRAÚDO PARA FABRICAÇÃO DE CONCRETO
}

\author{
Diego Faleiros Lopes ' \\ André Carlos Silva ' \\ Mariana Rezende de Barros ' \\ Elenice Maria Schons Silva '
}

\section{Resumo}

Desde meados de 2014 o setor de construção civil brasileiro vem enfrentando uma severa recessão econômica. Contudo, a demanda por matérias-primas para a fabricação de concreto continua alta, sobretudo por agregados. Isto se deve ao fato de que aproximadamente 70 a $80 \%$ do volume de concreto é composto por areia e brita. Só no ano de 2014 estima-se que 740 milhões de toneladas de brita e areia foram consumidas no Brasil pela construção civil. Já no ano de 2015 este mesmo consumo foi reduzido para 519 milhões de toneladas. A adoção de matérias-primas inovadoras, com alta qualidade, baixo preço e menores impactos ambientais em sua cadeia produtiva é fundamental para o aumento da sustentabilidade no setor da construção civil. $O$ objetivo do presente trabalho foi caracterizar física e quimicamente estéreis proveniente do setor mineral do sudeste goiano seguindo a norma NBR 72I I/2009 da $A B N T$, visando seu uso como agregado graúdo para concreto. Quatro amostras de $100 \mathrm{~kg}$ foram coletadas de diferentes litologias e classificadas por peneiramento a seco para obtenção de quatro tipos de brita (0, I, 2 e 3). Foram determinados a massa específica, massa unitária compactada, absorção de água, teor de argila e de materiais friáveis, resistência mecânica, conteúdo de material fino, distribuição granulométrica e índice de forma. Todas as amostras foram aprovadas nos ensaios e, portanto, o material apresenta características que permitem seu uso como agregado graúdo na construção civil.

Palavras-chave: Agregado graúdo; Brita; Construção civil; Estéril de mineração.

\section{MINING WASTE REUSE AS COARSE AGGREGATE FOR CONCRETE PRODUCTION}

\begin{abstract}
Since mid-20I4, the Brazilian construction sector has been facing a severe economic recession. However, the demand for raw materials for concrete production remains high, especially for aggregates. This is because approximately $70-80 \%$ of the concrete volume is made up of gravel and sand. It is estimated that 740 million tons of gravel and sand were consumed in Brazil by civil construction in 20I4. However, in 2015 this same consumption was reduced to 519 million tons. The adoption of innovative raw materials with high quality, low price, and lower environmental impacts in its production chain is of paramount importance for increasing the sustainability in the construction sector. The aim of this work was to characterize physically and chemically waste rocks from mines located on the southeastern part of the Goiás state in order to use them as coarse aggregates for concrete. The technical standard NBR 721 I/2009, published by the Brazilian Association of Technical Standards (ABNT) was used. Four samples of $100 \mathrm{~kg}$ were collected from different lithologies and classified by dry screening to obtain four different gravel types $(0,1,2$, and 3$)$. Specific mass, compacted unit mass, water absorption, clay and friable material content, mechanical strength, fine material content, particle size distribution, and shape index were determined. All samples passed the tests and, therefore, the waste rocks has features that allow them to be used as coarse aggregates in civil construction.
\end{abstract}

Keywords: Coarse aggregates; Gravel; Civil construction sector; Mining waste rock.

'Laboratório de Modelamento e Processamento Mineral, Universidade Federal de Goiás - UFG, Catalão, GO, Brasil. E-mail: dfaleiros@outlook.com

2176-1523 (c) 2020 Associação Brasileira de Metalurgia, Materiais e Mineração. Publicado pela ABM. Este é um artigo de acesso aberto distribuído sob os termos da licença Creative Commons CC BY-NC-ND (Attribution-NonCommercial-NoDerivs) - https:// creativecommons.org/licenses/by-nc-nd/4.0/. 


\section{INTRODUÇÃO}

Apesar do setor da construção civil passar por um período de estagnação desde meados de 2014 , o mesmo vem mostrando um acréscimo em suas atividades construtivas e produtivas nos últimos anos. Isso se deve principalmente ao aumento da população e à necessidade de obras de infraestrutura, cada vez mais modernas e eficientes. Os agregados são materiais (naturais e/ou artificiais) mais consumidos pela indústria da construção civil. São considerados como materiais granulares, resistentes, sem forma e volume bem definidos e de dimensões variadas [I]. Os agregados são compostos por grãos limpos de minerais ou rochas de alta dureza, isentos de produtos químicos ou de recobrimento superficial de argila e outros materiais finos, uma vez que tais finos podem causar a deterioração do concreto. São classificados em agregados graúdos (também chamados de brita) e miúdos (areia), sendo responsáveis por 70 a $80 \%$ do volume total do concreto [2]. Segundo a Associação Nacional das Entidades de Produtores de Agregados para Construção (ANEPAC) [3], o setor de agregados para indústria da construção civil apresentou em 2014 uma produção de aproximadamente 740 milhões de toneladas de brita e areia. Em 2015 o setor sofreu uma retração de aproximadamente $70 \%$, fechando em 519 milhões de toneladas.

O setor da mineração é um ramo da economia que vem progressivamente crescendo nos últimos anos. Com isso, este mercado tornou-se extremamente competitivo. A diminuição de custos operacionais, implantação de melhorias em seus processos, a busca pelo aproveitamento de materiais que até então eram descartados na fase de lavra e processamento mineral, é uma realidade neste setor, com potencial para tornar-se soluções interessantes para o uso no desenvolvimento de novas tecnologias e produtos [4]. $O$ aumento no consumo de agregados e as iniciativas sustentáveis na produção dos recursos minerais têm fomentado iniciativas inovadoras, tais como a adoção de minerais e rochas que possuam especificações técnicas adequadas e que tornem as construções civis mais eficientes e econômicas [5].
A exaustão dos agregados convencionais, principalmente os de natureza aluvionar, tem se mostrado um problema cada vez mais concreto em diversas áreas do território brasileiro. Soma-se à isso os impactos ambientais promovidos pela dragagem de leitos de rios para a produção de areia e o aumento entre as distâncias médias entre os polos produtores (pedreiras ou dos portos de areia) e o mercado consumidor [6]. Desta forma, o uso de agregados não convencionais (ou alternativos) se releva uma alternativa atraente e promissora.

As etapas de lavra e de processamento mineral geram, como via de regra, grandes quantidades de estéreis e rejeitos, sendo estes classificados com materiais de baixo, ou mesmo nenhum, valor econômico associado. Contudo, tais materiais devem ser dispostos em pilhas e barragens, gerando inexoravelmente impactos ambientais, riscos e custos. As empresas mineradoras situadas na macro região de Catalão/GO, no sudeste goiano, são responsáveis por produzir um volume superior a $2800 \mathrm{t} /$ dia de estéreis, que são dispostos em pilhas e que não tem teores de minerais úteis que permitam seu processamento. Desta forma, a necessidade da realização de pesquisas que visem uma utilização destes materiais, de modo a torná-los coprodutos, é real tem potencial para promover melhorias sociais e ambientais.

O presente trabalho apresenta pela primeira vez na literatura, salvo melhor entendimento dos autores, resultados de ensaios de caracterização de estéril da lavra de quatro formações geológicas presentes no complexo alcalino Catalão I, visando sua utilização como agregado graúdo (brita) para concreto. Os testes foram realizados em conformidade com a norma NBR 72 I I/2009 [7].

\section{MATERIAIS E MÉTODOS}

\section{I Caracterização do Material Estéril}

As amostras minerais usadas no presente trabalho foram doadas por uma mineradora localizada no complexo alcalino Catalão I. Amostras de quatro litologias diferentes foram coletadas. As mesmas foram identificadas como

Tabela I. Ensaios de caracterização realizados e normas técnicas que descrevem a metodologia adotada nos mesmos

\begin{tabular}{|c|c|}
\hline Normas utilizadas nos ensaios de caracterização & Laboratóric \\
\hline Determinação da composição granulométrica, módulo de finura e a dimensão máxima característica (NBR 248/2003 [8]) & LaMPPMin \\
\hline Determinação da massa específica, massa específica aparente e absorção de água (NBR NM 53/2003 [9]) & LaMPPMin \\
\hline Índice de forma de agregado graúdo pelo método do paquímetro (NBR 7809/2016 [10]) & LaMPPMin \\
\hline Determinação da massa unitária compactada do agregado graúdo (NBR NM 45/2006 [I I ]) & LaMPPMin \\
\hline Determinação do teor de argila em torrões e materiais friáveis (NBR 72। 8/20I0 [I2]) & LaMPPMin \\
\hline Determinação do material fino que passa através da peneira $75 \mu \mathrm{m}$ por lavagem (NBR NM 46/2003 [I3]) & LaMPPMin \\
\hline Resistência ao choque Treton (NBR 5564/20I I [14]) & Falcão Bauer \\
\hline Abrasão Los Angeles (NBR NM 5I/200 I [I5]) & Falcão Bauer \\
\hline Durabilidade pelo emprego de soluções de sulfato de sódio e de magnésio (DNER ME 089/I994 [16]) & Falcão Bauer \\
\hline
\end{tabular}


carbonatada (ou amostra A), silicatada (B), intemperizada (C) e expurgo do moinho de bolas (D). As amostras $A, B$ e C eram originárias de diferentes frentes de lavras da mesma mina e a amostra $D$ era composta por um material granulado, produzido pelo moinho de bolas durante a sua operação e que não possui valor econômico. A Figura I apresenta uma foto das amostras ensaiadas. A Tabela I sumariza os ensaios de caracterização realizados, conforme proposto na norma NBR 72। I/2009 [7], realizados no Laboratório de Modelamento e Pesquisa em Processamento Mineral (LaMPPMin) da Regional Catalão da Universidade Federal de Goiás e no Centro Tecnológico de Controle da Qualidade (CTCQ) da Falcão Bauer.

Amostras de $100 \mathrm{~kg}$ de cada amostra foram coletadas conforme estabelecido pela NBR NM 26/200I [17], homogeneizadas e quarteadas de acordo com a NBR NM 27/200 I [18]. Alíquotas das amostras foram peneiradas à seco [8] para enquadramento na norma NBR 72। I/2009 [7] em britada $0(-12,50+4,75 \mathrm{~mm})$, I $(-25,00+9,50 \mathrm{~mm})$,
$2(-31,50+19 \mathrm{~mm})$ ou $3(-50+25 \mathrm{~mm})$. Uma alíquota composta por partes iguais em peso das amostras e classificada como brita I, foi enviada para o CTCQ da Falcão Bauer, com o intuito de verificar a durabilidade e resistência mecânica das mesmas. Foram realizados ensaios de resistência ao choque (Treton), abrasão Los Angeles e durabilidade pelo emprego de soluções de sulfato de sódio e de magnésio. O ensaio Treton [14] foi realizado com 20 partículas, visando classificar os agregados com relação à sua utilização em concretos ou em base e sub-base de pavimentos asfálticos. Segundo Scandiuzzi e Andriolo [19], o ensaio Los Angeles [15] visa determinar a resistência dos agregados ao desgaste por fricção, avaliando também a resistência dos mesmos à degradação devido ao manuseio, estocagem e mistura. O ensaio de durabilidade pelo emprego de soluções de sulfato de sódio e de magnésio foi realizado em cinco ciclos, conforme norma DNER ME 089/1994 [16], objetivando determinar a resistência dos agregados à ação do tempo. Todos testes foram realizados em triplicata.

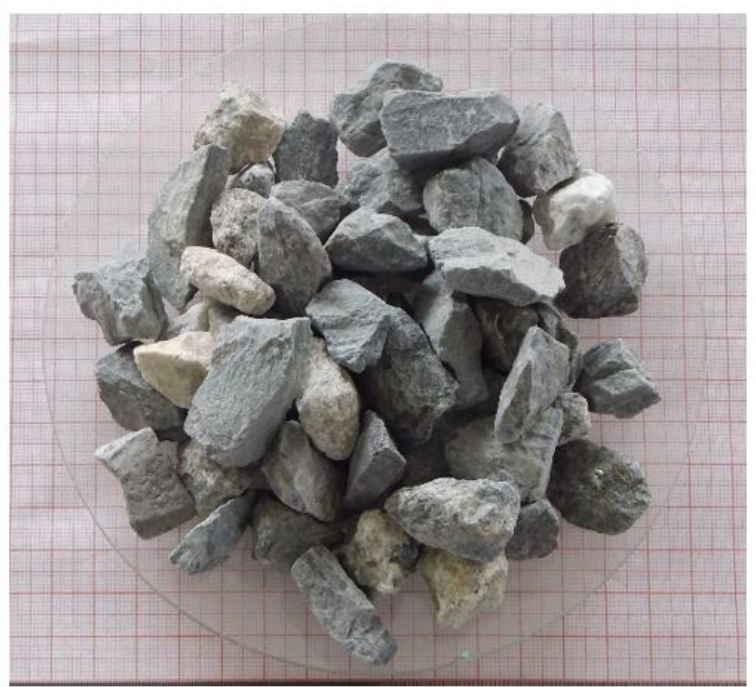

(a)

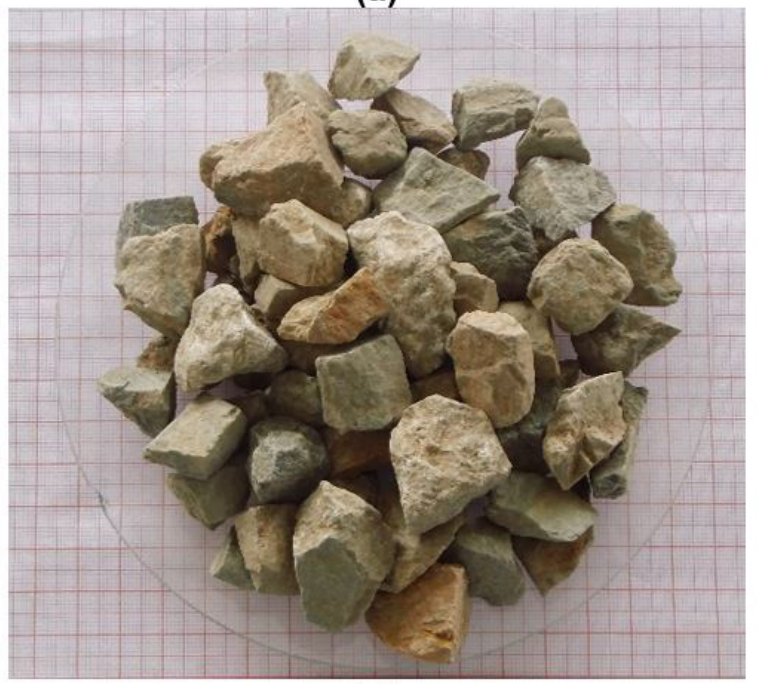

(c)

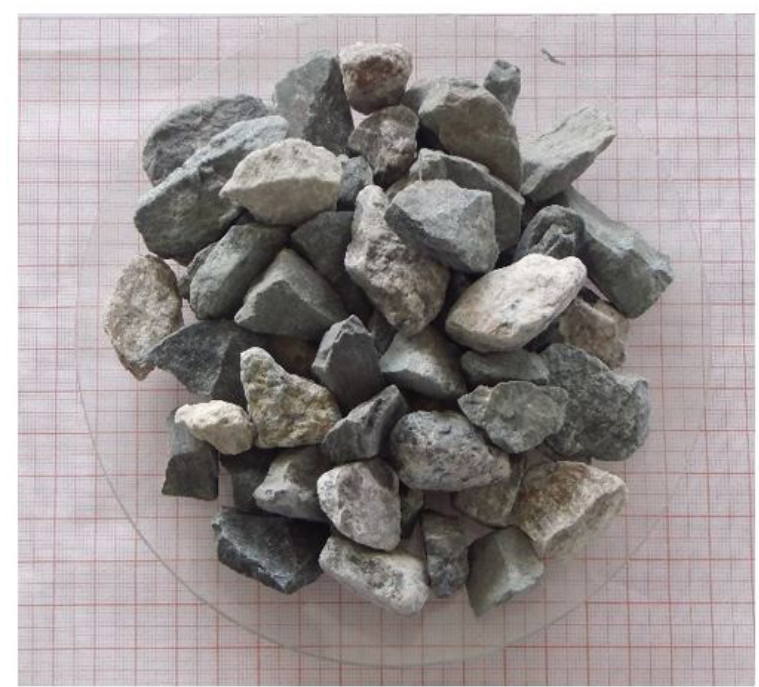

(b)

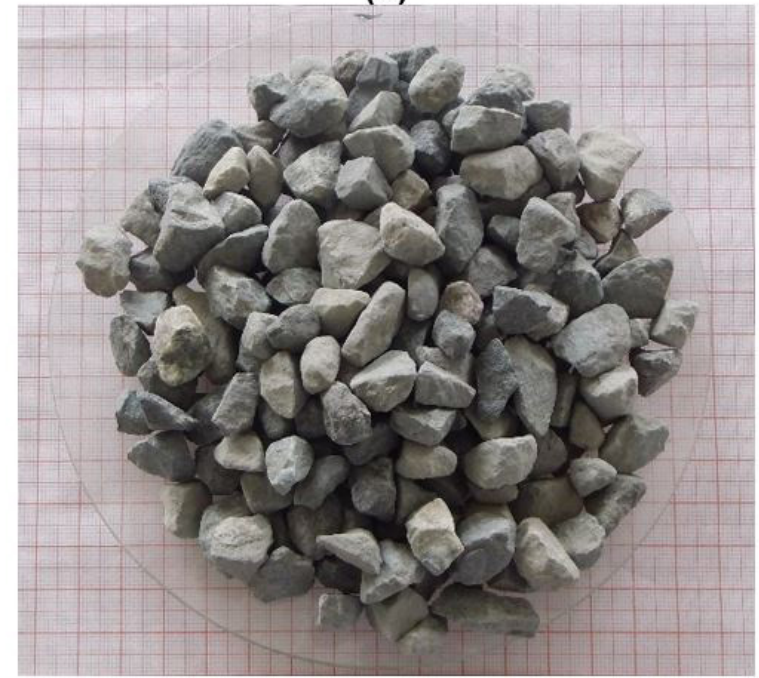

(d)

Figura I. Amostras utilizadas nos ensaios de caracterização in natura: (a) carbonatada; (b) silicatada; (c) intemperizada e (d) expurgo do moinho de bolas. 


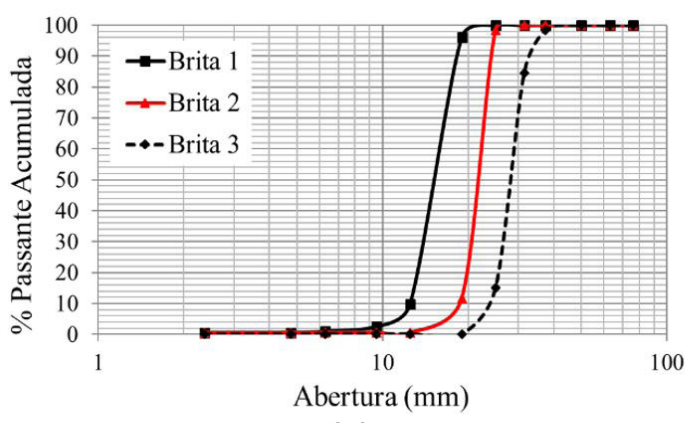

(a)

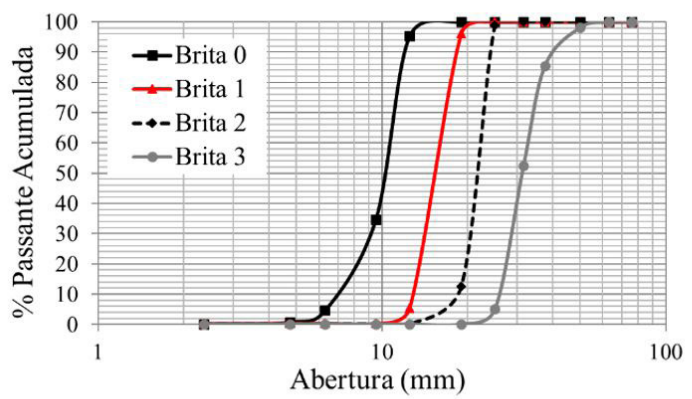

(c)

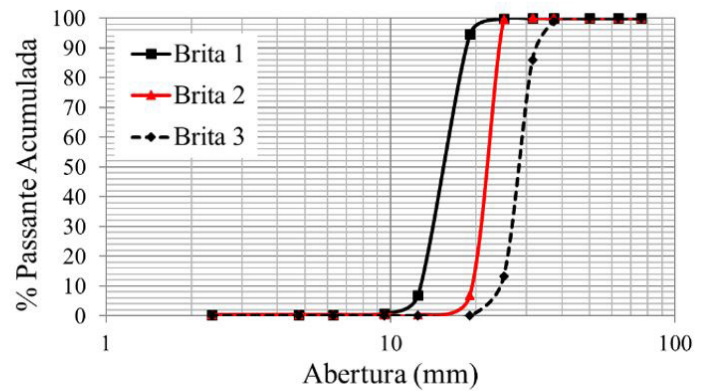

(b)

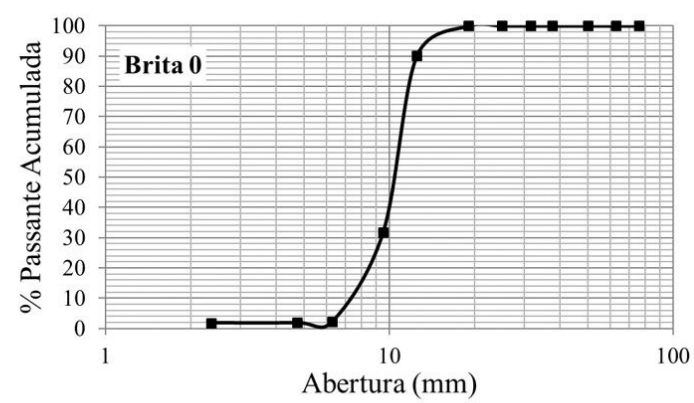

(d)

Figura 2. Distribuição granulométrica das amostras: (a) carbonatada; (b) silicatada; (c) intemperizada e (d) expurgo do moinho de bolas.

\section{RESULTADOS E DISCUSSÃO}

A Figura 2 apresenta a distribuição granulométrica das amostras após adequação nas faixas granulométricas de brita (0 à 3), conforme norma NBR 72। I [7]. As amostras $A$ e $B$ possuíam grãos na faixa granulométrica de brita I, 2 e 3. Já a amostra $C$ se encontrava em faixas granulométricas compatíveis com britas $0,1,2$ e 3 , sendo este material o que apresentou distribuição granulométrica mais ampla das amostras ensaiadas. $A$ amostra $D$ foi classificada como brita 0 , sendo a amostra mais fina ensaiada. Este resultado já era esperado, uma vez que este material foi submetido a etapas de moagem. Pode-se observar que as dimensões das britas produzidas estão de acordo com a norma NBR 721।/2009 [7] e, assim sendo, são adequadas para fabricação de concretos e obras de pavimentação.

De acordo com Bauer [20], a massa específica está relacionada à massa dos grãos do agregado em um determinado volume sem considerar os poros e os espaços vazios formados entre eles. A Figura 3 apresenta os resultados médios encontrados para as massas específicas das amostras ensaiadas, divididos nas frações de britas produzidas. Segundo Mehta e Monteiro [2I], a massa especifica de agregados derivados de rochas, frequentemente utilizados na construção civil, varia de $2,60 \mathrm{~g} / \mathrm{cm}^{3}$ à $2,70 \mathrm{~g} / \mathrm{cm}^{3}$. Os resultados encontrados variaram de 2,63 $\pm 0,08 \mathrm{~g} / \mathrm{cm}^{3}$ à $2,78 \pm 0,01 \mathrm{~g} / \mathrm{cm}^{3}$. Nota-se que independente da amostra e da faixa granulométrica considerada as massas especificas obtidas possuíam valores semelhantes, com desvio padrão máximo de $0,08 \mathrm{~g} / \mathrm{cm}^{3}$.

Segundo Mehta e Monteiro [2I], a massa unitária aproximada dos agregados normais varia

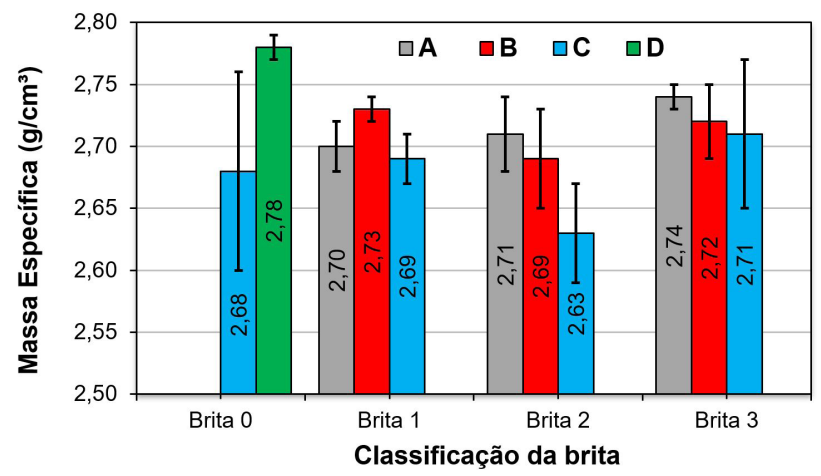

Figura 3. Massas específicas médias das amostras ensaiadas.

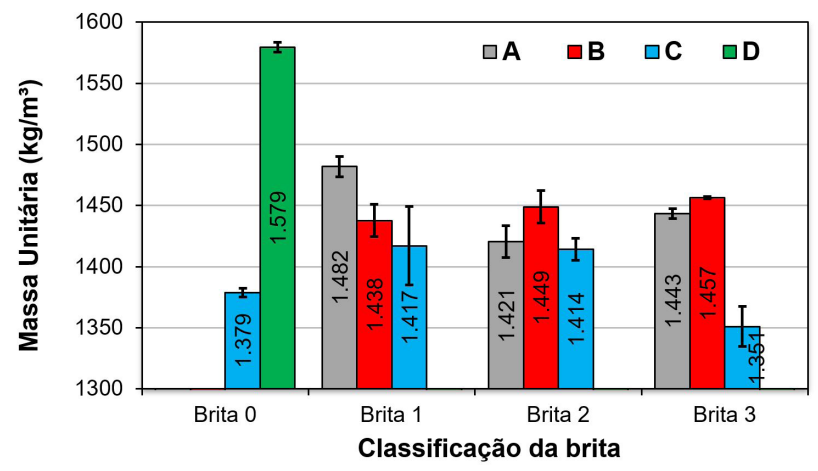

Figura 4. Massa unitária média das amostras ensaiadas.

entre 1200 e $1800 \mathrm{~kg} / \mathrm{m}^{3}$. Todas amostras ensaiadas apresentaram valores médios dentro desta faixa, variando de $1378,70 \pm 3,69 \mathrm{~kg} / \mathrm{m}^{3}$ à $1579,47 \pm 4,14 \mathrm{~kg} / \mathrm{m}^{3}$, como pode ser visto na Figura 4. 


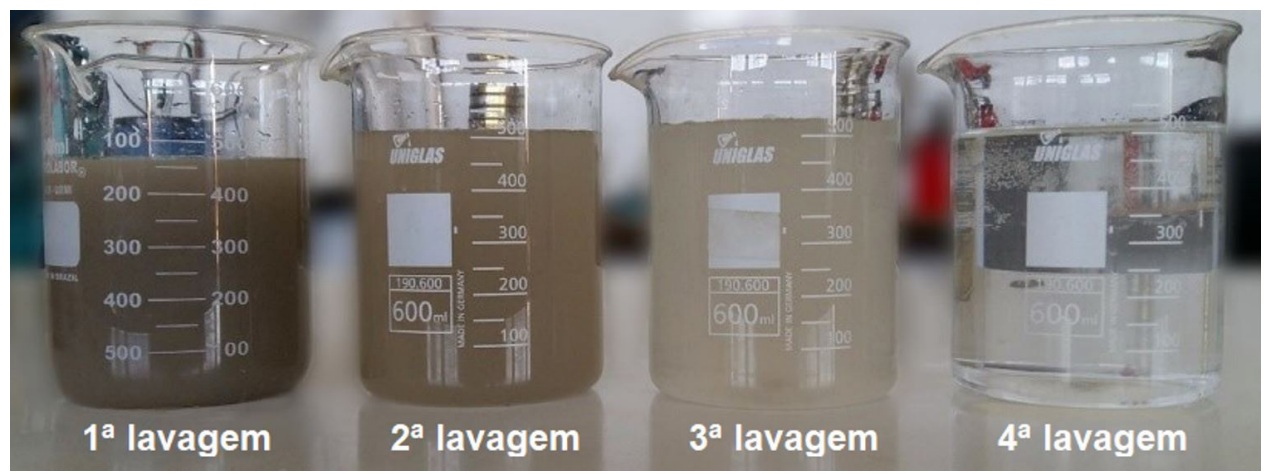

Figura 5. Exemplo de amostras de água coletadas após etapas de lavagem das britas.

A Figura 5 apresenta exemplos de amostras de água coletadas após etapas de lavagem das britas, realizadas de acordo com a norma NBR NM 46/2003 [13]. Percebe-se a nítida redução na turbidez da água de lavagem à partir do $3^{\circ}$ ciclo de lavagem. A presença de material particulado no agregado graúdo pode causar efeitos deletérios no concreto, afetando a sua trabalhabilidade e aumentando a demanda de água [2 I]. Segundo a norma NBR 72 I I/2009 [7] o limite máximo permitido de material particulado no agregado graúdo é de $1 \%$. Nota-se na Figura 6 que as britas I e 2 da amostra silicatada (B) e a brita 0 do expurgo do moinho de bolas (D), apresentaram valores acima de $\mathrm{I} \%$ (I,86\%, I, I $9 \%$ e I, $58 \%$, respectivamente). Desta forma, tais britas só podem ser comercializadas após lavagem, de modo à promover a remoção da fração fina. Outra solução seria a realização do peneiramento do material à úmido, de modo a bitolar o material nas faixas adequadas das britas, removendo a fração fina presente no mesmo.

A Figura 7 apresenta os resultados médios do testes de absorção de água. Nota-se que as amostras testadas apresentaram índices entre $0,89 \%$ e $2,70 \%$. Segundo a norma NBR 72 I I/2009 [7], agregados produzidos à partir de rochas com absorção de água inferior a $1 \%$, determinados conforme a ABNT NBR NM 53/2003, o limite de material fino presente no mesmo pode ser alterado de $1 \%$ para $2 \%$. Como as britas I e 2 da amostra silicatada (B) e a brita 0 do expurgo do moinho de bolas (D), apresentaram índices de absorção de água inferiores a $1 \%(0,99 \%, 0,96 \%$ e $0,89 \%$, respectivamente) estas podem ser consideradas aprovadas no testes de quantidade de material fino passante na peneira $75 \mu \mathrm{m}$ por lavagem.

De acordo com Mehta e Monteiro [2I], torrões de argila e materiais friáveis, alteram as características granulométricas dos agregados graúdos e geram prejuízo na resistência do próprio agregado e do concreto com ele fabricado. Ainda além, a presença de torrões de argila e materiais friáveis altera a aparência do concreto aparente, podendo ocasionar manchas em sua superfície. Segundo a norma NBR 72II [7], a porcentagem de torrões de argila e materiais friáveis presentes nos agregados deve ser inferior a 3,0\%. Todas amostras testas foram aprovadas neste teste, uma vez que os valores obtidos ficaram entre $0,38 \%$ e $0,70 \%$ (vide Figura 8 ).

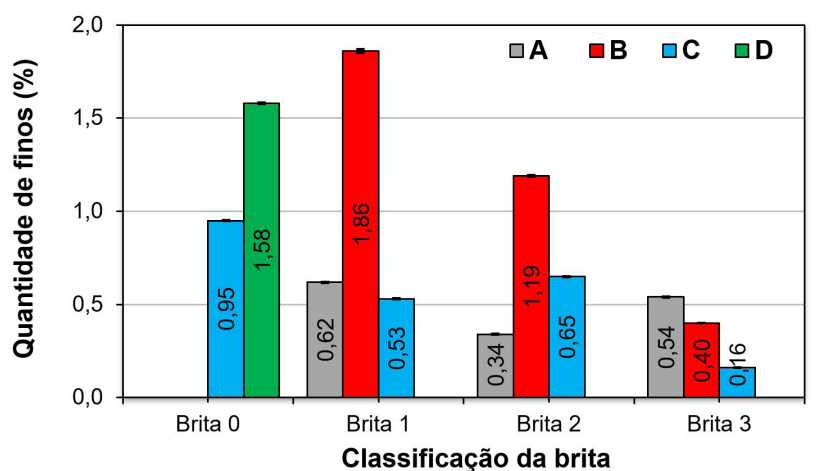

Figura 6. Resultados médios da quantidade material fino passante na peneira de $75 \mu \mathrm{m}$ por lavagem.

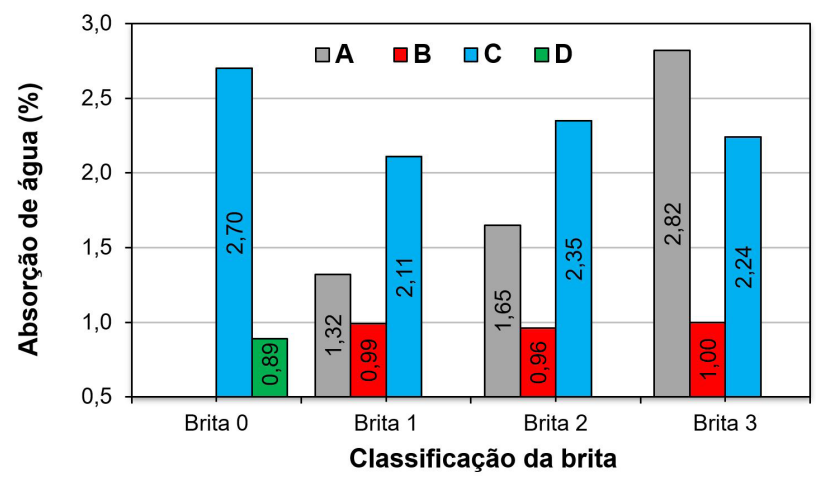

Figura 7. Resultados médios dos testes de absorção de água.

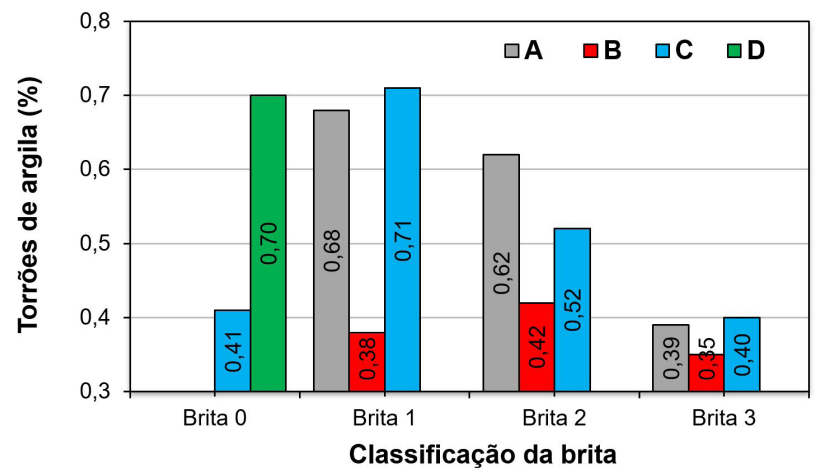

Figura 8. Resultados médios de torrões argila e materiais friáveis presentes nas amostras. 


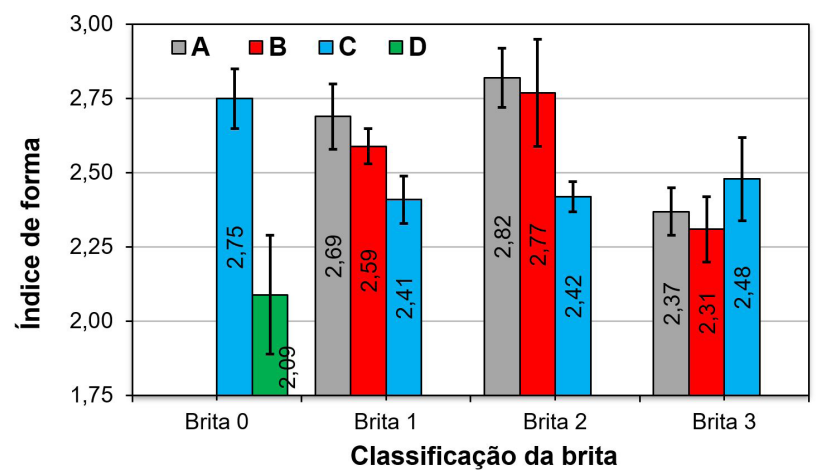

Figura 9. Resultados dos ensaios de índice e forma dos agregados graúdos pelo método do paquímetro.

Tabela 2. Resultados do ensaio de determinação de perda ao choque no aparelho Treton

\begin{tabular}{cccccc}
\hline CP n $^{\circ}$ & $\begin{array}{c}\mathbf{N}^{\circ} \text { de } \\
\text { Partículas }\end{array}$ & $\begin{array}{c}\text { Massa } \\
\text { inicial } \\
(\mathbf{g})\end{array}$ & $\begin{array}{c}\text { Massa } \\
\text { final } \\
\mathbf{( g )}\end{array}$ & $\begin{array}{c}\text { Diferença } \\
\mathbf{( g )}\end{array}$ & $\begin{array}{c}\text { Perda ao } \\
\text { choque no } \\
\text { aparelho } \\
\text { Treton (\%) }\end{array}$ \\
\hline 01 & 20 & 158,00 & 146,12 & 11,88 & 7,52 \\
02 & 20 & 159,00 & 149,13 & 10,12 & 6,35 \\
03 & 20 & 164,60 & 149,05 & 15,55 & 9,45 \\
Média & & & & & $7,77 \pm 1,27$ \\
\hline
\end{tabular}

$\mathrm{CP}=$ Corpo de prova.

Tabela 3. Índice médio de desgaste por abrasão Los Angeles

\begin{tabular}{cc}
\hline Nome do Componente & Resultado \\
\hline Graduação & Graduação G \\
Número de esferas & I I \\
Abrasão (\%) & 19,54 \\
\hline
\end{tabular}

De acordo com Borba e Santos [22], índice de forma dos grãos do agregado graúdo indica a similaridade que o mesmo possui com um cubo. Tal forma garante $o$ intertravamento do agregado graúdo quando compactado, aumentando a sua resistência ao cisalhamento. Segundo a NBR 721 I/2009 [7], o índice de forma de um agregado graúdo, determinado de acordo com a norma NBR 7809/2016 [10], deve ser inferior a 3. A Figura 9 apresenta os índices de forma médios encontrados para as amostras testadas. É possível perceber que todas amostras passaram no teste, uma vez que estas possuíam índice de forma menor que o estabelecido em norma.

Segundo a norma NBR 5564/20 I I [14], o agregado graúdo deve obter no ensaio de resistência ao choque pelo aparelho Treton de perda de massa de até $60 \%$. A Tabela 2 apresenta os resultados obtidos para três corpos de prova (CP). A amostra de brita I ensaiada obteve perda ao choque média de $7,77 \pm 1,27 \%$, sendo assim considerada aprovada neste teste.

A Tabela 3 apresenta os resultados médios do índice de desgaste por abrasão Los Angeles, realizado de acordo com a norma NBR NM 5I/200 I [I5]. A amostra analisada apresentou uma resistência a abrasão igual a 19,54\%, índice este considerado satisfatório uma vez que a norma
NBR 72। I/2009 [7] estipula que a porcentagem de perda de massa deve ser inferior a $50 \%$.

Com relação ao índice de durabilidade a amostra apresentou, em média, índice de desintegração de $0,22 \%$ para a solução de sulfato de sódio e $0,17 \%$ para a solução de sulfato de magnésio. De acordo com a norma DNER ME 089// 994 [16], os limites máximos admissíveis são de $20 \%$ para a solução de sulfato de sódio e de $30 \%$ para a solução de sulfato de magnésio. Desta forma a amostra testada não apresenta nenhuma restrição quanto à desintegração em presença destes sulfatos.

\section{CONCLUSÕES}

Quatro amostras de rocha oriundas de atividades minerarias do sudeste goiano foram caracterizadas com fins do seu uso como agregado graúdo para a construção civil. Não se recomenda a utilização destas rochas in natura, uma vez que as mesmas se encontram em uma ampla faixa granulométrica e com considerável presença de partículas finas, o que pode influenciar negativamente em algumas propriedades de concretos formulados com estes agregados, tais como a sua trabalhabilidade, resistência mecânica e mesmo aspectos visuais.

As amostras separadas em frações adequadas de britas ( 0 a 3 ) foram aprovaram nos ensaios de caracterização física. Devido à questões mercadológicas (preço e demanda) sugere-se a britagem seguida de peneiramento a úmido do material, de modo a adequando-o às faixas granulométricas de britas 0 e $\mathrm{I}$. A remoção dos materiais pulverulentos via peneiramento à úmido é uma ação importante, visto que o excesso deste material pode prejudicar a aderência dos grãos dos agregados com a pasta de cimento, diminuindo assim a resistência mecânica de concretos e argamassas. Os resultados obtidos após a classificação nas faixas granulométricas e a remoção dos materiais pulverulentos indicam que mesmo com um blend entre as amostras se enquadraria nos requisitos da norma NBR 72 I I/2009 [7]. Assim sendo, os resultados obtidos demostraram que as rochas testadas apresentaram características semelhantes aos agregados graúdos (brita) atualmente utilizados na indústria da construção civil brasileira para fabricação de concreto e obras de pavimentação.

Trabalhos futuros serão realizados, tais como a moldagem de corpos de provas de concreto com substituição parcial e total do agregado graúdo pelo estéril, visando analisar a resistência mecânica do concreto.

\section{Agradecimentos}

Os autores agradecem às agências brasileiras de fomento CNPq e CAPES, e em especial à FAPEG pela bolsa de mestrado, indispensável para a realização deste estudo. Ainda além, agradecemos ao LaMPPMin e à Universidade Federal de Goiás pela permissão de realização deste trabalho e ao Centro de Controle da Qualidade da Falcão Bauer pela parceria. 


\section{REFERÊNCIAS}

I La Serna HAL, Rezende MM. Agregados para construção civil. Brasília: Departamento Nacional de Produção Mineral; 2009 [acesso em 15 dez. 20 I6]. Disponível em: https://sistemas.dnpm.gov.br/publicacao/mostra_imagem. asp?IDBancoArquivoArquivo $=4008$

2 Portland Cement Association. Aggregates. Illinois: PCA; 2017 [acesso em I5 jan. 20I7]. Disponível em: http://www. cement.org/cement-concrete-basics/concrete-materials/aggregates

3 Associação Nacional das Entidades de Produtores de Agregados para Construção. Mercado: perspectivas para o Setor de Agregados. São Paulo: ANEPAC; 2016 [acesso em 12 dez. 2016]. Disponível em: http://www.anepac.org. br/agregados/mercado

4 Mendes MVA. Aproveitamento de finos de magnetita gerados no processamento de rocha fosfática [monografia]. Catalão: Universidade Federal de Goiás; 2016.

5 Carlete BA, Castro NF, Silva HV. Caracterização de agregados minerais provenientes de resíduos grosseiros de rochas ornamentais. In: Anais da 24a Jornada de Iniciação Científica; 2016; Rio de Janeiro. Rio de Janeiro: CETEM/ MCTIC; 2016. p. I6I-165. Jornada de Iniciação Científica - CETEM, 2016, p. I6I-I65.

6 Luz AB, Almeida SLM. Manual de agregados para construção civil. 2. ed. Rio de Janeiro: CETEM/MCT; 2012.

7 Associação Brasileira de Normas Técnicas. NBR 72। I/2009: agregados para concreto: especificação. Rio de Janeiro: ABNT; 2009.

8 Associação Brasileira de Normas Técnicas. NBR 248: agregados: determinação da composição granulométrica. Rio de Janeiro: ABNT; 2003.

9 Associação Brasileira de Normas Técnicas. NBR NM 53/2003: agregado graúdo: determinação de massa específica, massa específica aparente e absorção de água. Rio de Janeiro: ABNT; 2003.

10 Associação Brasileira de Normas Técnicas. NBR 7809/2016: agregados graúdo: determinação do índice de forma pelo método do paquímetro: método de ensaio. Rio de Janeiro: ABNT; 2005.

II Associação Brasileira de Normas Técnicas. NBR NM 45/2006: agregados: determinação da massa unitária e do volume de vazios. Rio de Janeiro: ABNT; 2006.

12 Associação Brasileira de Normas Técnicas. NBR 7218/2010: agregados: determinação do teor de argila em torrões e materiais friáveis. Rio de Janeiro: ABNT; 2010.

13 Associação Brasileira de Normas Técnicas. NBR NM 46/2003: determinação do material fino que passa através da peneira $75 \mu \mathrm{m}$, por lavagem. Rio de Janeiro: ABNT; 2003.

14 Associação Brasileira de Normas Técnicas. NBR 5564/20 I I: lastro ferroviário: métodos e requisitos de ensaios: determinação da resistencia ao choque: anexo E. Rio de Janeiro: ABNT; $201 \mathrm{I}$.

15 Associação Brasileira de Normas Técnicas. NBR NM 5I/200 I: agregado graúdo: ensaio de abrasão "Los Angeles". Rio de Janeiro: ABNT; 2001.

16 Departamento Nacional de Estrada e Rodagem. DNER ME 089/1994: avaliação da durabilidade pelo emprego de soluções de sulfato de sódio ou de magnésio. Rio de Janeiro: DNER; 1994.

17 Associação Brasileira de Normas Técnicas. NBR NM 26/200 I: agregados: amostragem. Rio de Janeiro: ABNT; 200 I.

18 Associação Brasileira de Normas Técnicas. NBR NM 27/200 I: agregados: redução da amostra de campo para ensaios de laboratório. Rio de Janeiro: ABNT; 2001.

19 Scandiuzzi L, Andriolo FR. Concreto e seus materiais: propriedades e ensaios. São Paulo: PINI; 1986.

20 Bauer LAF. Materiais de construção. 5. ed. Rio de Janeiro: LTC; 20I0. vol. 2.

2I Mehta PK, Monteiro PJM. Concreto: microestruturas, propriedades e materiais. 2. ed. São Paulo: Nicole Pagan Hasparyk; 2014.

22 Borba VQ, Santos AA. Projeto de base drenante realizado de acordo com a especificação técnica DER/SP ET-DEP00/008 [trabalho de conclusão de curso]. Criciúma: Universidade do Extremo Sul Catarinense; 2013.

Recebido em: 19 Set. 2019

Aceito em: 4 Out. 2019 